\title{
Elevated advanced oxidation protein products levels in patients with liver cirrhosis
}

\author{
Jolanta Zuwała-Jagiełło ${ }^{\boxplus}$, Monika Pazgan-Simon², Krzysztof Simon² \\ and Maria Warwas ${ }^{1}$ \\ ${ }^{1}$ Department of Pharmaceutical Biochemistry, ${ }^{2}$ Clinic of Infectious Diseases, Liver Diseases and Acquired Im- \\ mune Deficiency, Wroctaw Medical University, Wroctaw, Poland
}

Received: 29 June, 2009; revised: 11 November, 2009; accepted: 26 November, 2009

available on-line: 09 December, 2009

\begin{abstract}
Serum concentrations of advanced oxidation protein products (AOPPs) and glycation end products (AGEs) were assessed with respect to functional compromise of liver, as determined by the Child-Pugh and MELD scores. Patients with decompensated liver cirrhosis (Child-Pugh B and C) exhibited significantly higher serum concentrations of AOPPs than both patients with compensated liver cirrhosis (Child-Pugh A) and controls. The levels of plasma AGEs in all liver cirrhotic patients were higher when compared with those with the controls and this difference was statistically significant. Plasma total antioxidant status of the patients was significantly lower than that of controls. Significant positive correlations between AOPPs level and the MELD score and between the oxidative stress index and the MELD score were found in all patients with liver cirrhosis. Altered AOPPs levels in decompensated patients may influence the potency of oxidative stress and the progression of liver disease.
\end{abstract}

Keywords: advanced oxidation protein products, AGEs, cirrhosis

\section{INTRODUCTION}

Increasing evidence of free radical involvement is reported for many fibroproliferative diseases such as cirrhosis in human chronic liver diseases, pulmonary fibrosis, glomerulonephritis and atherosclerosis (Bedossa et al., 1994; Poli et al., 1997). Cirrhosis is characterized by inflammation of the liver, often caused by a rise in free radicals within the liver. Under normal circumstances, the liver maintains a supply of internal antioxidants to neutralize the free radicals generated by viruses and various endo- and exogenous compounds processed in the liver. However, when the liver antioxidants are low, or when the liver is overwhelmed by continued oxidative insults (e.g., long-lasting alcohol abuse or infection with hepatitis B virus and hepatitis C virus), the damage from free radicals increases, resulting in inflammation and the formation of scar tissue (fibrosis) (Czeczot et al., 2006; Valko et al., 2007). The persistence of profibrogenic factors, the progressive decrease of antioxidant reserves, the dysfunction of liver microcirculation through NO-mediated pathways, determine the shift to liver regeneration and cirrhosis.

Since free radicals have very short half-lives, the clinical assessment of oxidative stress is based on the measurement of different stable oxidized products of modified proteins, lipids, carbohydrates and nucleic acids. Proteins are susceptible to oxidant-mediated injury, forming cross-linkage and aggregation products that are resistant to proteolysis. Markers of protein oxidation were characterized by Witko-Sarsat et al. (1996), and named as advanced oxidation

\footnotetext{
$\square$ Corresponding author: Jolanta Zuwała-Jagiełło, Department of Pharmaceutical Biochemistry, Wrocław Medical University, Szewska 38/39, 50-139 Wrocław, Poland; e-mail: jagiellodr@interia.pl

Abbreviations: ABTS, 2,2'-azinobis-(3-ethylbenzothiazoline-6-sulfonate); AGEs, advanced glycation end products; ALT, alanine aminotransferase; AOPPs, advanced oxidation protein products; AP, alkaline phosphatase; AST, aspartate aminotransferase; $\mathrm{AU}$, arbitrary units; $\mathrm{CV}$, coefficient of variation; $\gamma \mathrm{GT}$, gamma glutamyltransferase; INR, international normalised ratio of prothrombin time; MELD, model for end-stage liver disease score; OSI, oxidative stress index; ROS, reactive oxygen species; TAS, total antioxidant status; VSMCs, vascular smooth muscle cells.
} 
protein products (AOPPs), since they share several homologies with advanced glycation end productsmodified proteins (AGEs-modified proteins), biomarkers of oxidative stress reflecting protein glycooxidation.

The major fate of plasma protein AGEs has been claimed to be clearance in the liver. Accumulation of AGEs in chronic liver disease has several toxic effects. Apart from direct damage to the structure of the extracellular matrix, they act via specific receptors, for example RAGE (receptor for advanced glycation end products). RAGE is expressed by hepatic stellate cells and myofibroblasts, which are the relevant cells for fibrogenesis of chronic liver disease. AGEs-RAGE interaction activates nuclear factor $\mathrm{NF}-\kappa \mathrm{B}$, which is followed by stimulation of transcription of genes for cytokines and growth factors, increased expression of adhesive molecules, increased vascular permeability and further toxic effects (reviewed in Hyogo \& Yamagishi, 2008).

Serum concentrations of AOPPs (closely correlating with AGEs levels) increase with progression of chronic diseases (Witko-Sarsat et al., 1996; 1998); therefore, AOPPs have been considered as novel disease-related biomarkers for oxidative stress. AOPPs are described as dityrosine containing cross-linked protein products. This definition is important, since it excludes protein aggregates that form as a result of disulfide links after a subtle oxidative stress. Therefore, the presence of AOPPs may be a good and more accurate biomarker of oxidative stress than lipid peroxidation products (Witko-Sarsat et al., 1996; Dalle-Donne et al., 2003).

During oxidative stress, endogenous mechanisms, enzymes and antioxidant molecules are deployed to destroy reactive oxygen species (ROS) and reduce the harmful effect of oxidants. Extra- and intracellular defense, targeted against transient damaging species can be grouped under several mechanisms and collectively they operate to terminate free radical reaction or remove reactive species and their secondary products (Gutteridge \& Halliwell, 1994). A number of methods have been developed to assess total antioxidant capacity, measuring each antioxidant component separately (Niki \& Noguchi, 2000). The accurate antioxidant capacity of the organism can be determined by the measurement of total antioxidant status (TAS) (Erel, 2004). Thus, TAS is a single measure that aims to describe the dynamic equilibrium between pro-oxidants and antioxidants in the plasma.

To the best of our knowledge there are no data available as to whether the serum level of AOPPs is elevated in liver in chronic liver disease. The aim of this study was to investigate whether serum levels of AOPPs and AGEs, and plasma total antioxidant status, are altered in patients with liver cirrhosis, and to assess their possible correlation with the severity of liver disease, measured by the Child-Pugh and the model for end-stage liver disease (MELD) scores. The per cent ratio of AOPPs level to TAS level was regarded as oxidative stress index (OSI).

\section{MATERIALS AND METHODS}

Patients. This study was performed in 34 patients with liver cirrhosis (20 men and 14 women, mean age $57.00 \pm 15$ years) admitted to the Clinic of Infectious Diseases, Liver Diseases and Acquired Immune Deficiency for evaluation. The diagnosis of liver cirrhosis was based on clinical, laboratory and ultrasonographic findings or histological criteria. The baseline laboratory findings of the patients with liver cirrhosis (classified as Child-Pugh A, B and C) are provided in Table 1 . The patients were classified as having compensated $(n=16)$ or decompensated liver cirrhosis $(n=18)$. According to the Child-Pugh scores, all compensated patients belonged to class A. The decompensated group consisted of 8 patients in class $\mathrm{C}$ and 8 patients in class $\mathrm{B}$ with a Child-Pugh score above 8 . At the time of the study no ChildPugh A patients showed clinical features of decompensated liver cirrhosis (ascites, edema or hepatic encephalopathy). All patients graded Child-Pugh B$\mathrm{C}$ had moderate to severe ascites without evidence of infection. The predominant etiology of cirrhosis in 18 cases of cirrhosis was alcohol abuse, while chronic viral hepatitis was the cause in 10 cases, and six remained of cryptogenic origin.

Exclusion criteria were concurrent use of antioxidant drugs; co-existing diseases like diabetes mellitus, chronic kidney disease or hepatocellular carcinoma; alcohol use within previous two weeks; gastrointestinal bleed or blood transfusion within previous two weeks. The control group consisted of 30 healthy subjects (14 men and 16 women, mean age $55.8 \pm 18$ years) with normal laboratory findings. The consent of the Bioethics Committee of the Wrockaw Medical University was obtained and all patients were informed about the character of analyses made. Studies were conducted in compliance with the ethical standards formulated at the Helsinki Declaration of 1975 (revised in 1983).

Methods. Peripheral venous blood from fasted healthy volunteers and fasted cirrhotic patients was collected in separate tubes, one containing the anticoagulant EDTA and the other without serum anticoagulant. The blood was allowed to clot for $30 \mathrm{~min}$ at $25^{\circ} \mathrm{C}$, centrifuged at $2000 \times \mathrm{g}$ for $15 \mathrm{~min}$ at room temperature, and the serum was then separated and aliquoted into tubes for storage. To obtain plasma samples, the blood was centrifuged immediately at 
$2000 \times g$ for $10 \mathrm{~min}$ at $4^{\circ} \mathrm{C}$, and then aliquoted into tubes. The tubes were then stored frozen at $-80^{\circ} \mathrm{C}$ until they were used to study different parameters.

Determination of serum AOPPs. Determination of AOPPs was based on spectrophotometric detection according to Witko-Sarsat et al. (1996). Twohundred microliters of plasma diluted $1: 5$ in $20 \mathrm{mM}$ phosphate buffer, $\mathrm{pH} 7.4$, containing $0.9 \%$ sodium chloride (PBS), or chloramine-T standard solutions ( 0 to $100 \mu \mathrm{mol} / \mathrm{L}$ ), were placed in each well of a 96well microtiter plate (Becton Dickinson Labware, Lincoln Park, NJ, USA), and followed by $20 \mu \mathrm{l}$ of $10 \%$ acetic acid. Ten microliters of $1.16 \mathrm{M}$ potassium iodide (Sigma) were then added, followed by 20 $\mu \mathrm{L}$ of $10 \%$ acetic acid. The absorbance of the reaction mixture was immediately read at $340 \mathrm{~nm}$ in a microplate reader against a blank containing $200 \mu \mathrm{l}$ of PBS, $10 \mu \mathrm{L}$ of $\mathrm{KI}$ and $20 \mu \mathrm{L}$ of $10 \%$ acetic acid. The chloramine- $\mathrm{T}$ absorbance at $340 \mathrm{~nm}$ was linear within the range of 0 to $100 \mu \mathrm{mol} / \mathrm{L}$. AOPP concentrations were expressed in $\mu \mathrm{mol} / \mathrm{L}$ of chloramine- $\mathrm{T}$ equivalents. Coefficient of variation $(\mathrm{CV})$ served as the indicator of precision. Intra-day and inter-day $\mathrm{CV}$ values were $<10 \%$.

Determination of AGEs by fluorescence spectroscopy. AGEs were measured by fluorescence according to the method of Munch et al. (1997). Serum samples were diluted 100-fold in PBS and filtered $(0.22 \mu \mathrm{m}$, Millex-GV; Millipore, Bedford, MA, USA). Fluorescence spectra (corrected for background) were recorded in triplicate on a Perkin-Elmer LS50B Luminescence spectrometer at room temp. Emission and excitation slit widths were set to $1 \mathrm{~nm}$. When excitation was performed at $370 \mathrm{~nm}$, an emission maximum was found at $445 \mathrm{~nm}$. To compare different sera, the excitation wavelength was set to $370 \mathrm{~nm}$ and the signal intensity was measured at the emission maximum of $445 \mathrm{~nm}$. Total serum fluorescent AGEs was expressed as relative fluorescence intensity in arbitrary units (AU).

Measurement of the total antioxidant status of plasma. The plasma antioxidant capacity was measured using a commercially available TAS kit (Randox Laboratories, Crumlin, UK). The TAS assay is based on the TEAC (Trolox Equivalent Antioxidant Capacity) method, reported by Rice-Evans and Miller (1994). It is based on the inhibition by antioxidants of the absorbance of the radical cation of 2,2'-azinobis-(3-ethylbenzothiazoline-6-sulfonate) (ABTS) formed by the interaction of ABTS with ferrylmyoglobin radical species. Upon the addition of a plasma sample, the oxidative reactions initiated by the hydroxyl radicals present in the reaction mix are suppressed by the antioxidant components of the plasma, preventing the color change and thereby providing an effective measure of the total antioxidant capacity of the plasma. TAS results are ex- pressed as $\mathrm{mmol} / \mathrm{L}$, and the precision of this assay is excellent, being lower than 3\% (Cao \& Prior, 1998).

Oxidative stress index. The per cent ratio of the AOPPs level to the TAS level gave the oxidative stress index (OSI), an indicator of the degree of oxidative stress (Harma et al., 2003).

Measurement of individual antioxidants. Serum albumin, uric acid and bilirubin concentrations were measured by using commercial kits (Abbott, Irving, TX, USA). Vitamin C concentration was measured by using FRASC (total ferric reducing activity and ascorbate concentration measurement) method (Benzie \& Strain, 1999).

Model for end-stage liver disease (MELD) score. The model for end-stage liver disease (MELD) score was calculated from the following equation:

$9.57 \times \log _{\mathrm{e}}$ (creatinine $\left.\mathrm{mg} / \mathrm{dL}\right)+3.78 \times \log _{\mathrm{e}}$ (total bilirubin $\mathrm{mg} / \mathrm{dL})+11.2 \times \log _{\mathrm{e}}$ (international normalized ratio-INR) +6.43 (constant for liver disease etiology).

The maximal creatinine concentration considered in the MELD score is $4.0 \mathrm{mg} / \mathrm{dL}$ (Huo et al., 2006).

Statistical analysis. Comparison of the parameters between two different groups was conducted with the Mann-Whitney $U$ test and with the Kruskal-Wallis analysis of variances (ANOVA) for multiple comparisons. Coefficient correlations were evaluated using linear regression analysis or Pearson correlation. All results are expressed as means \pm S.D. and median values. Statistical significance was established at $P<0.05$.

\section{RESULTS}

The concentrations of serum AOPPs, AGEs and the different parameters in the cirrhotic patients are shown in Table 2, with corresponding levels in controls. There were statistically significant differences between the four groups. In healthy controls, the serum AOPP and AGEs were similar to those in control groups in other studies (Sebekova et al., 2002; Kalousová et al., 2003).

Patients with decompensated liver cirrhosis (Child-Pugh B and C) exhibited significantly higher serum concentrations of AOPPs than patients with compensated liver cirrhosis (Child-Pugh A) and controls $(P<0.05)($ Table 2$)$. There was a significant difference in serum AOPPs concentrations between control subjects and compensated liver cirrhotic patients $(P<0.001)$. The levels of plasma AGEs in all liver cirrhotic patients were higher than those of the controls and this difference was statistically significant $(P<0.001)$ (Table 2$)$. The levels of plasma AGEs 
Table 1. Laboratory findings in patients with liver cirrhosis

\begin{tabular}{llll}
\hline & Child-Pugh A & Child-Pugh B & Child-Pugh C \\
\hline (n) & 16 & 10 & 8 \\
\hline $\begin{array}{l}\text { ALT (IU/L) } \\
\text { Reference values 0-40 }\end{array}$ & & & \\
Mean \pm S.D. & $38.51 \pm 22.76$ & $54.19 \pm 25.86$ & $39.78 \pm 19.79$ \\
$\begin{array}{l}\text { AST (IU/L) } \\
\text { Reference values 0-40 }\end{array}$ & & \\
Mean \pm S.D. & $54.0 \pm 29.48$ & $103.13 \pm 43.63$ & $81.68 \pm 62.90$ \\
$\gamma$ GT (IU/L) & & \\
$\begin{array}{l}\text { Reference values 5-36 } \\
\text { Mean } \pm \text { S.D. }\end{array}$ & $256.05 \pm 200.53$ & $268.43 \pm 213.16$ & $182.29 \pm 148.42$ \\
AP (IU/L) & & & \\
Reference values 30-90 & & & \\
Mean \pm S.D. & $105.19 \pm 20.74$ & $127.91 \pm 67.63$ & $1167.41 \pm 42.3$ \\
Creatinine (mg/dL) & & & \\
Reference values 0.6-1.3 & & $1.34 \pm 0.53$ & $1.77 \pm 0.60$ \\
$\begin{array}{l}\text { Mean } \pm \text { S.D. } \\
\text { INR }\end{array}$ & $1.05 \pm 0.35$ & & \\
Reference values 0.8-1.1 & & & \\
Mean \pm S.D. & $0.96 \pm 0.13$ & $1.22 \pm 0.10$ & $2.23 \pm 0.66$ \\
MELD & & & $24.10 \pm 6.98$ \\
Reference values 6-8 & & $15.90 \pm 7.20$ & \\
Mean \pm S.D. & $7.79 \pm 2.55$ & & \\
\hline
\end{tabular}

Table 2. Serum concentrations of AOPPs, AGEs and antioxidative parameters in healthy controls and in patients with liver cirrhosis (Child-Pugh A, B and C).

\begin{tabular}{|c|c|c|c|}
\hline & Healthy controls & Child-Pugh A & $\begin{array}{l}\text { Child-Pugh } \\
\text { B and C }\end{array}$ \\
\hline (n) & 30 & 16 & 18 \\
\hline \multicolumn{4}{|c|}{ AOPP $(\mu \mathrm{mol} / \mathrm{L})$} \\
\hline Mean \pm S.D. & $100.2 \pm 44.0$ & $125.0 \pm 38^{*+}$ & $218.0 \pm 69^{*}$ \\
\hline Median & 93.2 & 128.0 & 209.6 \\
\hline \multicolumn{4}{|c|}{ AGEs [AU $\left.\left(\times 10^{5}\right)\right]$} \\
\hline Mean \pm S.D. & $0.86 \pm 0.35$ & $1.58 \pm 0.48^{* *}$ & $1.83 \pm 0.72 * *$ \\
\hline Median & 0.85 & 1.44 & 1.92 \\
\hline \multicolumn{4}{|c|}{ Albumin (mg/dL) } \\
\hline Mean \pm S.D. & $4.74 \pm 0.23$ & $3.2 \pm 0.23^{*}$ & $2.65 \pm 0.55^{*}$ \\
\hline Median & 4.27 & 3.0 & 2.3 \\
\hline \multicolumn{4}{|c|}{ Bilirubin (mg/dL) } \\
\hline Mean \pm S.D. & $0.80 \pm 0.15$ & $1.03 \pm 0.1$ & $2.34 \pm 1.29$ \\
\hline Median & 0.75 & 1.01 & 2.15 \\
\hline \multicolumn{4}{|c|}{ Vitamin $C(\mu \mathrm{mol} / \mathrm{L})$} \\
\hline Mean \pm S.D. & $54.26 \pm 16.25$ & $46.17 \pm 17.9$ & $41.73 \pm 12.5$ \\
\hline Median & 54.26 & 47.09 & 36.92 \\
\hline \multicolumn{4}{|c|}{ Uric acid (mmol/L) } \\
\hline Mean \pm S.D. & $0.32 \pm 0.072$ & $0.30 \pm 0.04^{*}$ & $0.25 \pm 0.06$ \\
\hline Median & 0.35 & 0.31 & 0.18 \\
\hline \multicolumn{4}{|c|}{ TAS (mmol/L) } \\
\hline Mean \pm S.D. & $1.31 \pm 0.17$ & $0.80 \pm 0.22^{* *}$ & $0.67 \pm 0.16^{* *}$ \\
\hline Median & 1.31 & 0.86 & 0.45 \\
\hline \multicolumn{4}{|c|}{ OSI $_{\mathrm{AOPP}}$ (arbitrary unit) } \\
\hline Mean \pm S.D. & $0.80 \pm 0.30$ & $1.70 \pm 0.80^{* *+}$ & $3.20 \pm 0.50^{* *}$ \\
\hline Median & 0.70 & 1.40 & 2.60 \\
\hline \multicolumn{4}{|l|}{ MELD } \\
\hline Mean \pm S.D. & $6-8$ & $8.31 \pm 2.55^{*++}$ & $20.2 \pm 8.25^{*}$ \\
\hline Median & & 8.0 & 19.0 \\
\hline
\end{tabular}

${ }^{*} \boldsymbol{P}<0.05 ;{ }^{* *} P<0.001$ vs. healthy controls; ${ }^{+} P<0.05 ;{ }^{+} P<0.001$ vs. Child-Pugh B and C. in patients with decompensated cirrhosis were higher than those in compensated cirrhosis, but this difference was not statistically significant.

As seen in Table 2, while all individual parameters of the antioxidative status tend to decrease, only the decrease of uric acid was statistically significant. Plasma TAS of the patients was significantly lower than in controls $(P<0.001)$. The decrease in the plasma levels of TAS was most prominent in decompensated liver cirrhotic patients. The difference between patients with Child-Pugh B and C cirrhosis and patients with Child-Pugh A cirrhosis in respect to TAS was not statistically significant. There was a markedly increased oxidative stress index in patients with Child-Pugh $B$ and $C$ cirrhosis compared with patients with Child-Pugh A cirrhosis or controls $(P<0.05, P<0.001$, respectively).

There was no statistically significant correlation between ALT levels and TAS and AOPPs level in cirrhotic patients or controls.

The MELD scores were determined in the 34 patients with liver cirrhosis (Table 2). These were higher in the decompensated patients than in the compensated cirrhotic patients $(P<0.001)$. Significant correlations between AOPPs levels and MELD scores $(r=0.43, P<0.05)$ and between OSI and MELD scores $(r=$ $0.38, P<0.01)$ were observed among the cirrhotic patients belonging to all three Child-Pugh classes.

\section{DISCUSSION}

In this study we show that patients with decompensated liver cirrhosis have higher concentrations of AOPPs than compensated patients and that there are positive correlation between the MELD score on the one hand and AOPPs level and the degree of oxidative stress (oxidative stress index) on the other. Our findings suggest that AOPPs and AGEs-modified pro- 
teins may contribute to progressive liver disease in these patients and influence the potency of oxidative stress.

A role of oxidative stress in the pathogenesis of chronic liver disease has been proposed by several authors (Romero et al., 1998; Yadav et al., 2002; Loguercio \& Federico, 2003; Bandara et al., 2005; Koike \& Miyoshi, 2006). Studies have shown increased plasma levels of markers of lipid peroxidation and reduced plasma antioxidant content. Protein oxidation products are increasingly being used as markers instead of lipid peroxidation products in demonstrating oxidative stress (Dalle-Donne et al., 2003). AOPPs measurements reflect the free radical generation and the degree of protein oxidation (Witko-Sarsat et al., 1996). ROS can play a role in the development of chronic liver disease by damaging cell constituents in the liver and causing fibrosis and cirrhosis (Bolukbas et al., 2005; Denzer \& Lüth, 2009). It was reported that AOPPs generated by different oxidation patterns lead to the production of either hydrogen peroxide or nitric oxide (Servettaz et al., 2007). Nitric oxide can interact with ROS to form other reactive nitrogen species. These reactive nitrogen species secondarily promote important reactions such as nitrosation, oxidation or nitration, leading to impaired cellular functions and enhanced inflammatory reactions (Friedman, 2000; Wiest \& Groszmann, 2002). AOPPs are referred to as markers of oxidative stress as well as markers of neutrophil activation in chronic disease (Witko-Sarsat et al., 2003). It has thus been shown that chlorinated oxidants of neutrophil origin may lead to oxidative stress, notably protein oxidation. Once formed, such AOPPs foci create a nidus for the amplification of oxidative stress. In addition to increased formation, decreased removal/detoxification of AOPPs may contribute to stress. There is increasing evidence that the liver plays important roles in the elimination of AOPPs (Iwao et al., 2006). In patients with chronic liver diseases, constriction of the sinusoidal blood stream leads to the development of portal hypertension with portocaval shunts (Svistounov \& Smedsrød, 2004). The hindrance of substance exchange between hepatocytes and the sinusoidal blood stream could increase serum level of AOPPs in these patients. Therefore, the liver, especially in cirrhotic patients, cannot prevent the accumulation of AOPPs effectively. Finally, our findings extended the results of Oettl et al. (2008) which suggested that albumin is oxidatively modified in patients with advanced liver disease depending on its severity.

In previous studies (Zuwała-Jagiełło et al., 2006; 2007; Górka et al., 2008), a cross-sectional survey of patients with various forms of viral hepatitis demonstrated a close association between high serum levels of AGEs and the inflammatory lesions of the liver with any morphologically evident cir- rhosis. In this study, we examined serum AGEs in the patients with liver cirrhosis for the purposes of evaluating their application as markers of the severity of liver cirrhosis of various etiologies. In our clinical population, patients with Child B and C cirrhosis had elevated AGEs values compared to those with Child A cirrhosis. On the other hand, a positive correlation was found between AOPPs levels and MELD scores in all three Child-Pugh classes, but no correlation between AOPPs and AGEs was found in either decompensated or compensated cirrhotic patients. Very recently, AGEs have been found to act as proinflammatory factors (Sparvero et al., 2009). Nevertheless, AOPPs are believed to be more closely related to inflammation than AGEs, whose receptors participate in AOPPs-mediated signal transduction (Kalousová et al., 2005). These interactions enhance ROS formation, with nuclear factor NF- $\kappa B$ activation and release of proinflammatory cytokines, adhesion molecules, and growth factors (Hyogo \& Yamagishi, 2008). Furthermore, the experiments in cultured VSMCs (vascular smooth muscle cells) clearly established that AOPPs induce the expression of monocyte chemoattractant protein-1 (Peng et al., 2006), a molecule playing a significant role in the development of fibrosis (Marra et al., 1999). Owing to these effects, AOPPs and AGEs are assumed to have an important pathogenetic role in the complications of chronic liver disease (Sebekova et al., 2002; Kalousová et al., 2005).

The effects of various antioxidants in the plasma are additive and their cooperation protects the organism against attacks by free radicals (Willcox et al., 2004). Thus, in the present study, we have chosen to perform the measurement of TAS in plasma samples. In various disorders of the liver, decrease in TAS has been shown in the plasma samples (Bolukbas et al., 2005; Eissa et al., 2008). In our study patients with cirrhosis show a significantly lower TAS levels compared to the control group. However, AOPPs level and OSI was significantly higher in the decompensated patients than in the compensated cirrhotic patients or controls. There was also a positive correlation between the MELD score and the AOPPs level and OSI in cirrhotic patients, but no correlation between the MELD score and TAS. Recently, it has been reported that OSI may reflect the oxidative status more accurately than the total antioxidant status (Canakci et al., 2007). In addition, in a study by Fierbinteanu-Braticevici et al. (2002), the serum index of oxidative stress has been suggested as an independent risk factor for liver fibrosis. Our study also clearly demonstrates that the level of OSI is independently and positively associated with the severity of liver cirrhosis.

In summary, our study shows that patients with cirrhosis are exposed to oxidative stress and 
the potency of the oxidative stress is significantly related to the severity of liver cirrhosis of various etiologies. The report also describes AOPPs as a new serum biomarker useful in assessing the severity of liver cirrhosis. However, our findings emphasize the need for further investigations correlating the serum levels of AOPPs or AGEs seen in decompensated cirrhotic patients with their clinical outcomes (for example, renal failure, diabetes or septic complications) to develop prognostic parameters.

\section{Acknowledgements}

This work was financed by a grant No. 1777 from the Wrocław Medical University.

We thank Joanna Górka-Dynysiewicz, M.S. for skillful technical assistance.

\section{REFERENCES}

Bandara P, George J, McCaughan G, Naidoo D, Lux O, Salonikas C, Kench J, Byth K, Farrell GC (2005) Antioxidant levels in peripheral blood, disease activity and fibrotic stage in chronic hepatitis C. Liver Int 25: 518526.

Bedossa P, Houglum K, Trautwein C, Holstege A, Chojkier M (1994) Stimulation of collagen alpha 1(I) gene expression is associated with lipid peroxidation in hepatocellular injury: a link to tissue fibrosis? Hepatology 19: 1262-1271.

Benzie IF, Strain JJ (1999) Ferric reducing/antioxidant power assay: direct measure of total antioxidant activity of biological fluids and modified version for simultaneous measurement of total antioxidant power and ascorbic acid concentration. Meth Enzymol 299: 15-27.

Bolukbas C, Bolukbas FF, Horoz M, Aslan M, Celik H, Erel O (2005) Increased oxidative stress associated with the severity of the liver disease in various forms of hepatitis B virus infection. BMC Infect Dis 5: 95-102.

Canakci V, Yildirim A, Canakci CF, Eltas A, Cicek Y, Canakci $H$ (2007) Total antioxidant capacity and antioxidant enzymes in serum, saliva, and gingival crevicular fluid of preeclamptic women with and without periodontal disease. J Periodontol 78: 1602-1611.

Cao G, Prior RL (1998) Comparison of different analytical methods for assessing total antioxidant capacity of human serum. Clin Chem 44: 1309-1315.

Czeczot H, Scibior D, Skrzycki M, Podsiad M (2006) Glutathione and GSH-dependent enzymes in patients with liver cirrhosis and hepatocellular carcinoma. Acta Biochim Polon 53: 237-242.

Dalle-Donne I, Rossi R, Giustarini D, Milzani A, Colombo R (2003) Protein carbonyl groups as biomarkers of oxidative stress. Clin Chim Acta 329: 23-38.

Denzer UW, Lüth S (2009) Non-invasive diagnosis and monitoring of liver fibrosis and cirrhosis. Best Pract Res Clin Gastroenterol 23: 453-460.

Eissa LA, Gad LS, Rabie AM, El-Gayar AM (2008) Thrombopoietin level in patients with chronic liver diseases. Ann Hepatol 7: 235-244.

Erel O (2004) A novel automated method to measure total antioxidant response against potent free radical reactions. Clin Biochem 37: 112-119.
Fierbinteanu-Braticevici C, Bengus A, Neamtu M, Usvat R (2002) The risk factors of fibrosis in nonalcoholic steatohepatitis. Rom J Intern Med 40: 81-88.

Friedman SL (2000) Molecular regulation of hepatic fibrosis, an integrated cellular response to tissue injury. $J$ Biol Chem 275: 2247-2250.

Górka J, Zuwała-Jagiełło J, Pazgan-Simon M, Simon K, Warwas M (2008) Fluorescence of age in serum in detecting liver cirrhosis and hepatocellular carcinoma among patients with anti-HCV antibodies. Przegl Epidemiol 62: 393-400 (in Polish).

Gutteridge JM, Halliwell B (1994) Antioxidants in nutrition, health, and disease. pp 111-123. Oxford University Press, New York.

Harma M, Harma M, Erel O (2003) Increased oxidative stress in patients with hydatidiform mole. Swiss Med Wkly 133: 563-566.

Huo TI, Lin HC, Wu JC, Lee FY, Hou MC, Lee PC, Chang FY, Lee SD (2006) Proposal of a modified Child-Turcotte-Pugh scoring system and comparison with the model for end-stage liver disease for outcome prediction in patients with cirrhosis. Liver Transpl 12: 65-71.

Hyogo H, Yamagishi S (2008) Advanced glycation end products (AGEs) and their involvement in liver disease. Curr Pharm Des 14: 969-972.

Iwao Y, Anraku M, Hiraike M, Kawai K, Nakajou K, Kai T, Suenaga A, Otagiri M (2006) The structural and pharmacokinetic properties of oxidized human serum albumin, advanced oxidation protein products (AOPP). Drug Metab Pharmacokinet 21: 140-146.

Kalousová M, Sulková S, Fialová L, Soukupová J, Malbohan IM, Spacek P, Braun M, Mikulíková L, Fortová M, Horejsí M, Tesar V, Zima T (2003) Glycoxidation and inflammation in chronic haemodialysis patients. Nephrol Dial Transplant 18: 2577-2581.

Kalousová M, Zima T, Tesar V, Dusilová-Sulková S, Skrha J (2005) Advanced glycoxidation end products in chronic diseases-clinical chemistry and genetic background. Mutat Res 579: 37-46.

Koike K, Miyoshi H (2006) Oxidative stress and hepatitis C viral infection. Hepatol Res 34: 65-73.

Loguercio C, Federico A (2003) Oxidative stress in viral and alcoholic hepatitis. Free Radic Biol Med 34: 1-10.

Munch G, Keis R, Wessels A, Riederer P, Bahner U, Heidland, A, Niwa, T, Lemke HD, Schinzel R (1997) Determination of advanced glycation end products in serum by fluorescence spectroscopy and competitive ELISA. Eur J Clin Chem Clin Biochem 35: 669-677.

Niki, E, Noguchi N (2000) Evaluation of antioxidant capacity. What capacity is being measured by which method? IUBMB Life 50: 323-329.

Oettl K, Stadlbauer V, Petter F, Greilberger J, Putz-Bankuti C, Hallström S, Lackner C, Stauber RE (2008) Oxidative damage of albumin in advanced liver disease. Biochim Biophys Acta 1782: 469-473.

Peng K, Wu X, Zhao H, Sun Y (2006) Advanced oxidation protein products induce monocyte chemoattractant protein-1 expression via p38 mitogen-activated protein kinase activation in rat vascular smooth muscle cells. Chin Med J (Engl) 119: 1088-1093.

Poli G, Parola M (1997) Oxidative damage and fibrogenesis. Free Rad Biol Med 22: 287-305.

Rice-Evans C, Miller NJ (1994) Total antioxidant status in plasma and body fluids. Meth Enzymol 234: 279-293.

Romero MJ, Bosch-Morell F, Romero B, Rodrigo JM, Serra MA, Romero FJ (1998) Serum malondialdehyde: possible use for the clinical management of chronic hepatitis C patients. Free Radic Biol Med 25: 993-997. 
Sebekova KV, Kupcova R, Schinzel A, Heidland J (2002) Markedly elevated levels of plasma advanced glycation end products in patients with liver cirrhosis - amelioration by liver transplantation. J Hepatol 36: 66-71.

Servettaz A, Guilpain P, Goulvestre C, Chéreau C, Hercend C, Nicco C, Guillevin L, Weill B, Mouthon L, Batteux F (2007) Radical oxygen species production induced by advanced oxidation protein products predicts clinical evolution and response to treatment in systemic sclerosis. Ann Rheum Dis 66: 1202-1209.

Sparvero LJ, Asafu-Adjei D, Kang R, Tang D, Amin N, Im J, Rutledge R, Lin B, Amoscato AA, Zeh HJ, Lotze MT (2009) RAGE (receptor for advanced glycation endproducts), RAGE ligands, and their role in cancer and inflammation. J Transl Med 7: 17-38.

Svistounov D, Smedsrød BJ (2004) Hepatic clearance of advanced glycation end products (AGEs) - myth or truth? J Hepatol 41: 1038-1040.

Valko M, Leibfritz D, Moncol J, Cronin MT, Mazur M, Telser J (2007) Free radicals and antioxidants in normal physiological functions and human disease. Int $\mathrm{J}$ Biochem Cell Biol 39: 44-84.

Wiest R, Groszmann RJ (2002) The paradox of nitric oxide in cirrhosis and portal hypertension: too much, not enough. Hepatology 35: 478-491.

Willcox JK, Ash SL, Catignani GL (2004) Antioxidants and prevention of chronic disease. Crit Rev Food Sci Nutr 44: 275-295.

Witko-Sarsat V, Friedlander M, Capelliere-Blandin C, Nguyen-Khoa T, Nguyen AT, Zingraff J, Jungers P,
Descamps-Latscha B (1996) Advanced oxidation protein products as a novel marker of oxidative stress in uremia. Kidney Int 49: 1304-1313.

Witko-Sarsat V, Friedlander M, Khoa TN, Capeillere-Blandin C, Nguyen AT, Canteloup S, Dayer J-M, Jungers P, Drueke T, Descamps-Latscha B (1998) Advanced oxidation protein products as novel mediators of inflammation and monocyte activation in chronic renal failure. $J$ Immunol 161: 2524-2532.

Witko-Sarsat V, Gausson V, Nguyen A-T, Nguyen AT, Touam M, Drüeke T, Santangelo F, Descamps-Latscha B (2003) AOPP-induced activation of human neutrophil and monocyte oxidative metabolism: a potential target for $\mathrm{N}$-acetylcysteine treatment in dialysis patients. Kidney Int 64: 82-91.

Yadav D, Hertan HI, Schweitzer P, Norkus EP, Pitchumoni CS (2002) Serum and liver micronutrient antioxidants and serum oxidative stress in patients with chronic hepatitis C. Am J Gastroenterol 97: 2634-2639.

Zuwała-Jagiełło J, Simon K, Pazgan-Simon M, Kość-Czarny A, Warwas M (2006) Advanced glycation end products in serum of patients with chronic hepatitis and liver cirrhosis. Adv Clin Exp Med 2: 259-264.

Zuwała-Jagiełło J, Pazgan-Simon M, Górka J, Simon K, Milczarska J, Warwas M (2007) Serum advanced glycation end products and the development of hepatocellular carcinoma among HBV carriers. Pol J Environ Stud 16: 747-751 (in Polish). 